\title{
Letramento acadêmico e a construção de sentidos nas leituras de um gênero
}

\author{
Adriana Fischer* \\ Nilcéa Lemos Pelandré **
}

\section{Resumo}

O objetivo deste trabalho é caracterizar como as diferentes formas de leitura situada de um gênero contribuem para que alunos se assumam insiders em contexto acadêmico. Os dados em análise foram coletados em 2005 e 2006, em um curso brasileiro de licenciatura, através de observaçóes participantes e de entrevistas orais. Esses dados constituem parte dos eventos nomeados reflexivo-transformativos, incluindo leitura, produção e análise linguística do gênero discursivo crônica jornalística. Esses eventos também integram o modelo dialógico dos letramentos acadêmicos, que se reporta à construção de sentidos, à identidade, ao poder, à autoridade e à natureza institucional do que conta como conhecimento no contexto de um curso de Letras. Por se realizar um acompanhamento longitudinal do trabalho com leitura, discutem-se dados de duas alunas, relativos ao gênero crônica, em duas disciplinas acadêmicas. Os resultados comprovam que, para as alunas, são ferramentas de poder conhecer o funcionamento de um dado domínio social, no qual se insere o gênero destinado à leitura e à produção escrita, e desenvolver o metaconhecimento que o constitui, a fim de fazerem uso do letramento crítico e usarem os letramentos dominantes que dele fazem parte, na direção de se assumirem insiders no contexto acadêmico.

Palavras-chave: Leitura. Língua portuguesa-Gênero. Letramento.

* Doutora pelo Programa de Pós-Graduação em Linguística da Universidade Federal de Santa Catarina (UFSC). Investigadora Auxiliar, Centro de Investigação em Educação (CIEd) da Universidade do Minho, Braga, Portugal.

** Doutora pelo Programa de Pós-Graduação em Linguística da UFSC. Professora e pesquisadora do Programa de Pós-Graduação em Educação/CED/UFSC, Brasil. 


\section{Perspectivas sobre o letramento em Letras}

A complexidade do fenômeno do letramento é enfocada neste trabalho ${ }^{1}$ sob uma perspectiva sociocultural, que encontra lugar nos Novos Estudos do Letramento. O que justifica a caracterização "novos" a esses estudos é a ideia de que leitura, escrita e sentido são sempre situados em práticas sociais específicas, segundo Gee (2000). Acrescenta Lankshear (2002, p. 3 , tradução nossa), que esses "estudos do letramento privilegiam o sentido a habilidades mecânicas, o qual é compreendido muito mais em termos de processos socioculturais que estados ou eventos cognitivos internos."

Sentido, nessa projeção, simboliza a perspectiva (GEE, 2001, grifo do autor) que um sujeito letrado tem de si, dos outros, das relaçóes de poder e dos objetos/artefatos disponíveis para participar de práticas sociais. Pode indicar a esse sujeito sua "condição" (SOARES, 2002, p. 145) ou posição de insider ou outsider (GEE, 2001) em práticas sociais, que possibilitam a ele assumir ou não papéis sociais diversos nas interações. Reforça-se então o caráter social, situado e histórico do letramento, responsável por caracterizar a condição letrada de um sujeito, em um situado espaço da sociedade e em um particular momento histórico de sua trajetória pessoal e social.

Compreende-se assim que as linguagens em uso, por serem socialmente situadas em práticas sociais específicas, recebem a denominação de linguagens sociais, de acordo com Gee (1999, 2000). Estas linguagens guardam particularidades, como estilo, registro, padróes de vocabulário, sintaxe e conectores discursivos, pois se prendem a tipos específicos de atividades sociais e a identidades socialmente situadas.

$\mathrm{O}$ uso de linguagens sociais e especializadas em contexto acadêmico, especificamente em um curso de Letras, foco deste estudo, oportuniza aos alunos a construção mais situada de conhecimentos no processo dinâmico de "aceder, tratar e usar os textos" (DIONÍSIO, 2006, p. 26) ou, ainda, de assumir uma condição diante desse processo.

Argumenta-se que, por meio de interaçóes verbais, os alunos de um curso de Letras agem, pensam, valorizam e interagem de maneira conjunta, sincrônica com a linguagem, com vários artefatos e objetos, tais como os gêneros discursivos (BAKHTIN, 2003), "demonstrando quem são e o que estão fazendo diante dos outros e deles mesmos, em circunstâncias, tempos e lugares apropriados" (GEE, 1999, p. 129, grifos do autor). Assim, para 
irem se construindo sujeitos letrados em um curso de Letras, precisam, além de se inserirem em situaçôes sociais diversificadas, também desempenharem papéis na relação e na interação com os outros e com os objetos discursivos. É nas práticas situadas de uso das linguagens que se pode indicar e caracterizar como os alunos vão se assumindo insiders no contexto acadêmico. Nessas práticas, há possibilidades de caracterização mais precisa de como eles vão sendo socializados no que Gee $(1999,2001)$ nomeia de Discursos ${ }^{2}$.

Nos Discursos, inserem-se as linguagens sociais, as quais assumem relevância e sentido através deles. Nessa direção, os Discursos, com D maiúsculo, envolvem

modos de falar, ouvir, escrever, ler, agir, interagir, acreditar, valorizar, sentir e usar vários objetos, símbolos, imagens, ferramentas e tecnologias, com a finalidade de ativar identidades e atividades significativas, socialmente situadas. (GEE, 2001, p. 719, tradução nossa).

A natureza dos Discursos está diretamente relacionada aos contextos de letramento que a integram, às relaçóes de poder, às linguagens sociais e a todo aparato ideológico que os envolve, o que impulsiona Gee (1999) a caracterizá-los como primários e secundários. Os Discursos primários são os que os sujeitos "aprendem" na família e/ou na comunidade local. Os Discursos secundários envolvem instituições sociais (secundárias); pressupóem aprendizagem como parte da socialização; constituem, de forma reconhecida e significante, os atos públicos mais formais na sociedade; são responsáveis por construir e expandir os usos da linguagem, dos valores, atitudes, crenças adquiridos como parte dos primários. E, em função da relação que estabelecem com os variados contextos sociais, os letramentos podem ser dominantes. Essas posiçóes dos letramentos pressupóem a valorização estabelecida por determinadas instituiçóes sociais a certos Discursos secundários.

Considerando, então, que as práticas desenvolvidas em um curso de Letras englobam os Discursos secundários, bem como os letramentos dominantes, os quais as particularizam, enfoca-se, neste trabalho, um tipo específico de letramento: o acadêmico. $\mathrm{O}$ uso deste termo se tem relacionado aos contextos universitários, sobretudo aos respectivos eventos de letramento, 
para ressaltar a natureza especializada tanto dos textos que são veiculados e constroem o saber, como dos usos das linguagens que os materializam, dos papéis sociais de professores e de alunos, das finalidades de estes estarem nesse contexto específico e das relaçóes, muitas vezes implícitas, estabelecidas com o conhecimento (STREET, 2009). Todos esses aspectos, inevitavelmente, interrelacionam-se, pois o letramento, compreendido como práticas sociais, envolve (GEE, 1999, 2001) formas de ser, falar, ouvir, escrever, ler, agir, interagir, acreditar, valorizar, sentir, usar recursos, ferramentas, tecnologias capazes de ativar identidades relevantes num dado contexto.

Na visão de Boiarsky, Hagemann e Burdan (2003, p. 17, tradução nossa), "uma definição de letramento acadêmico precisa necessariamente incluir uma crença no pensamento crítico.” Este posicionamento dos autores decorre do valor que este domínio social concede a atividades de leitura e de escrita. Nesse ambiente, a comunidade acadêmica dá ênfase à independência de trabalho, autoconfiança, responsabilidade, relação desencadeada entre trabalho encaminhado por professores, alunos e ideias debatidas, incluindo a capacidade de os sujeitos desempenharem uma profissão atual ou posteriormente.

Sob essa ótica, é nos eventos de letramento acadêmico que os alunos vão construindo os seus saberes acadêmicos/científicos e, para além disso, também os posicionamentos ideológicos, significados culturais e estruturas de poder que, em conjunto, constituem o modo cultural de usar os textos. Em consequência, esses eventos são responsáveis por integrarem e participarem da construção do letramento acadêmico. Assim, nesse processo de construção, são geradas as condiçóes para a aquisição dos "padróes" do Discurso dominante da instituição. À medida que esta aquisição pode ser apenas parcial, em relação ao seu uso enquanto se está inserido, segundo, de certa forma, em um domínio que utiliza o Discurso dominante, tal Discurso pode ser visto como "reciclado", como nomeia Gee (1999, p. 147).

Uma outra dimensão do letramento em contexto acadêmico diz respeito ao letramento crítico que, em certa medida, através da capacitação crítica para o uso dos letramentos dominantes, concede "poder" aos sujeitos (GEE, 1999, p. 143). Letramento crítico, na visão deste autor, é o controle do uso de um Discurso secundário, que pressupóe a utilização 
de metaconhecimento, a fim de melhor compreender, analisar e criticar Discursos primários e/ou secundários e os modos como esses Discursos constituem os sujeitos letrados e os situam na sociedade.

Com o olhar voltado ao funcionamento de um curso de Letras, entende-se que os alunos necessitam aprender o metaconhecimento e, consequentemente, aprimorar o controle de uso de diferentes gêneros discursivos, ou seja, de Discursos secundários, na oralidade, na leitura e na produção escrita, bem como nas atividades de análise linguística, a fim de se assumirem insiders (GEE, 2001) nesse contexto acadêmico.

Metaconhecimento, de acordo com Lankshear (2002), referido nas abordagens anteriores, é o conhecimento sobre o que está envolvido na participação dos Discursos. É mais que meramente saber como agir ou ser capaz de se engajar de forma bem sucedida em uma prática de letramento particular, pressupóe entender a natureza de uma prática, suas crenças e seus valores constitutivos, seus significados e sentidos, como se relacionam com outras práticas, o que em específico proporciona a um sujeito um desempenho bem sucedido que o faz ter poder. $\mathrm{O}$ metaconhecimento dos Discursos, nesse sentido, contribui para ampliar a capacitação crítica no uso de um dado letramento.

Seguindo as posiçóes de letramento apresentadas até este momento, com destaque para a leitura e a escrita situadas, com e a partir de gêneros discursivos, entende-se, neste artigo, que não basta indicar simplesmente se um sujeito se torna letrado, conforme Hall (2002), em um determinado contexto social, tal como o acadêmico. $\mathrm{O}$ decisivo é compreender como o sujeito se torna letrado, o que aprende e como aprende o que é importante, essencial em contextos e práticas de leitura, escrita e oralidade, e como é reconhecido seu potencial de letramento.

\section{Abordagens metodológicas da pesquisa}

O presente trabalho ${ }^{3}$, visando à caracterização de leituras situadas do gênero crônica jornalística, por alunos ingressos em um curso de Letras, no estado de Santa Catarina, apresenta e discute movimentos dialógicos que marcam a construção de sentidos, pelas alunas Renata e Beatriz, em eventos de letramento acadêmico, nomeados por Fischer (2007) como reflexivo-transformativos. 
Os dados advindos do estudo de caso etnográfico (ANDRÉ, 2003) com essas duas alunas ganham destaque por haver um processo longitudinal de investigação, viabilizado pela observação participante no curso, em duas disciplinas, "Estudos da Língua Portuguesa I: conhecimentos básicos" (2005/1) e "Leitura e Produção Textual" (2005/2), por meio de entrevistas orais (2005 e 2006) e produçóes escritas. Nessas disciplinas, o professor (Tiago) adota práticas de letramento apoiadas nos gêneros discursivos, posicionando a leitura como suporte para a compreensão e a produçáo escrita de textos e como suporte direto às atividades de análise linguística e posterior reescrita de textos.

Diante dessa heterogeneidade de dados coletados, o foco da pesquisa é sociocultural, subordinando, dessa maneira, o individual e o social às condiçóes culturais dos alunos. Toda essa heterogeneidade metodológica é colaborativa ao processo de análise e sistematização dos dados, se for considerada "a natureza da relação do pesquisador com seu objeto de pesquisa.” (SOARES, 2006, p. 402). Neste caso, em que o trabalho caracteriza como as diferentes formas de leitura situada de um gênero contribuem para que alunos se assumam insiders em contexto acadêmico, focalizam-se essas formas de ler, que envolvem açóes, interaçóes, escolhas, atitudes, valoraçóes, crenças, construção de conhecimentos, não apenas em motivações sociais momentâneas decorridas no contexto acadêmico. Para além desse ambiente, considera-se que os alunos são constituídos como sujeitos letrados pela inserção e/ou participação em outros ambientes sociais, onde determinaçóes culturais assumem papel preponderante. Logo, não se pode desprezar a tentativa de, dentro dos limites da pesquisa, destinar o olhar ao contexto cultural mais amplo.

Considerando que em 120 horas/aulas de observaçóes participantes, nas duas disciplinas mencionadas do curso de Letras, muitos são os eventos de letramento acadêmico, estes, devido às regularidades das interaçóes, dos objetos textuais em uso, e para fins de análises dos dados, foram reunidos em três agrupamentos: Eventos interDiscursivos, Eventos identitários e Eventos reflexivo-transformativos, segundo Fischer (2007). Interessa este último agrupamento de eventos, em que a leitura situada, as produções escritas de crônicas e a construção dos respectivos sentidos têm seu lugar.

Os Eventos reflexivo-transformativos, conforme Fischer (2007), 
englobam situaçóes enunciativas em que os alunos valem-se do letramento crítico ou do Discurso reciclado, com as funçôes de libertação - de estruturas fechadas, impositivas de poder - e de emancipação - das práticas sociais em que participam e das próprias identidades assumidas por eles nestas práticas. Nessa direção, os eventos pertencentes a esse agrupamento permitem, aos alunos, o desenvolvimento do controle no uso de Discursos secundários e da metalinguagem que os constituem. Portanto, através da participação dos alunos de Letras nestes Eventos reflexivo-transformativos, abrem-se possibilidades para que eles analisem e questionem letramentos de maneira reflexiva e crítica, com o propósito de transformá-los, ao mesmo tempo em que transformam as suas próprias identidades sociais.

Como instrumento complementar de análise, no interior desses eventos de letramento, são enfocados os movimentos dialógicos dos alunos, a exemplo dos casos Renata e Beatriz, que podem ser indagatórios, confirmativos, exemplificativos, contrastivos, avaliativos e metalinguísticos. Esses movimentos representam formas de interação verbal e indicam especificamente os modos de participação dos alunos nos eventos de letramento, na relação com os o(s) outro(s) - os interlocutores da situação enunciativa - e com o conteúdo temático. Esses movimentos são decisivos para indicar, dessa forma, os modos de constituição letrada dos alunos ingressos em Letras.

Para que as discussóes apresentadas sejam bem compreendidas no seu propósito de realização, salienta-se que não se tem a pretensão de fazer análises exaustivas dos elementos constitutivos do gênero crônica jornalística, embora muitos desses elementos auxiliem no direcionamento das análises dos Eventos reflexivo-transformativos, especialmente no que tange às construçóes de sentido com e a partir da leitura do gênero.

\section{As leituras situadas de crônicas em Eventos reflexivo- transformativos}

Segundo Gee (1999), os Discursos dominantes impóem exigências mais rígidas quanto ao uso de objetos, de linguagem, de textos e quanto às formas de interação entre as pessoas. Desse modo, desenvolver e assumir o controle ou o domínio de uso de Discursos dominantes, como os que constituem as atividades no contexto acadêmico, requer empenho reflexivo 
e crítico por parte de alunos e professores. Nessas atividades, a construção de sentidos simboliza, por sua vez, um processo ativo e dinâmico, em que sujeitos interagem por meio da linguagem.

As reflexóes e as subsequentes transformaçóes nas práticas e nas próprias identidades das alunas Renata e Beatriz, nos Eventos reflexivotransformativos, ocorrem porque o professor viabiliza interaçóes efetivamente dialógicas em diversos eventos, em que propostas de trabalho fazem com que elas se assumam corresponsáveis no processo de construção de conhecimentos e de sentidos situados no contexto acadêmico. Para comprovar essa interlocução e os modos de constituição letrada das referidas alunas, apresentam-se diferentes eventos, envolvendo predominantemente a leitura de crônicas jornalísticas.

\section{Leitura e a análise inicial de exemplares de crônicas}

Um primeiro tipo de evento com a crônica, impulsionador de reflexôes, refere-se à análise de exemplares do gênero. A crônica jornalística inicial, disponibilizada pelo professor, é intitulada Festa no Apê, de um autor catarinense (M), publicada no início do ano de 2005 em um jornal de circulação estadual. Esta crônica é caracterizada, neste trabalho, como um gênero balizador, por ser o ponto de referência em muitas discussóes posteriores com tal gênero.

Como a análise de exemplares do gênero crônica (sequência 1, a seguir) dá-se no início do período letivo, aulas 2 e 3 de 2005/1, ganham destaque as marcas de experiências prévias na escolarização básica com este gênero, por meio de movimentos exemplificativos, realizados por Renata e Beatriz nas intervenções (falas) 6 e 8.

1. P4: Qual o objetivo do escritor ao publicar a crônica? [...] Quem o autor representa? Quem escreveu é o autor $M$, mas ele representa quem nessa crônica? $O$ autor $M$ ?

2. Renata: Os pais, no caso.

[Alunos comentam que podem ser as pessoas que não suportam mais ouvir a música.] 
3. P: Exatamente, ele se coloca no lugar das pessoas que não aguentam mais ouvir. 4. $A(R N)^{5}$ : Se ele não for convidado pelo jornal, pela revista, pra escrever ele não vai escrever, seria censurado na certa. [...]

5. P: Tanto é que essa crônica saiu agora, se ela saisse no fim do ano, dificilmente ela iria sair. [...]

6. Beatriz: Na escola, cada um tinha um livrinho chamado de crônicas, não tinha ironia, não tinha nada disso, o que era crônica, eram pequenas histórias contadas no cotidiano, o que aconteceu naquele dia, com aquela pessoa. Não eram criticas, ironias.

7. P: Talvez tivesse, mas como a situação que aconteceu não fechava com aquele momento, vocês não compreendiam.

8. Beatriz: Não eram bem histórias assim, eram historinhas que tinham. Temos que aprender a identificar o que é uma crônica.

9. P: Isso acontece, às vezes a pessoa diz que escreveu a crônica, pensa que é.

10. A (S): É, a gente levava o livrinho pra casa, lia e náo sabia o que era crônica. 11. P: Pode até ser, mas aquela ironia que está ali não estabelece relação nenhuma com a atualidade, foge. Então, depende do autor, ele vai construindo até que ele consegue que chegue na ironia. O gênero tem que ter certa regularidade.

12. Renata: Então o objetivo da revista em publicar uma crônica tem é de chamar a atenção do leitor?

13. P: Também é isso, mas eles dão uma "segurada", se eles perceberem que vai dar um processo. Quando um autor é muito famoso, escreve bastante, não tem problema. [...] A preocupação é da revista [...]

Conforme intervenção 2, de Renata, a compreensão sobre aspectos extraverbais do gênero crônica, como os possíveis interlocutores, é manifestada através de movimentos confirmativos às escolhas do professor nas orientaçóes de letramento desenvolvidas. Fazem-se presentes também os movimentos avaliativos, segundo palavras de Beatriz, na intervenção 8, ao tecer comparação com o trabalho já experienciado em anos anteriores (implicação do $e u$, das vivências escolares). A exemplo da intervenção 12, de Renata, as alunas realizam ainda movimentos indagatórios sobre o funcionamento da crônica, por estarem expostas a uma diferente abordagem com a crônica, que não a literária. 
Portanto, a diversidade de movimentos das alunas vai revelando o olhar atento sobre o que conta como letramento dominante em Letras, na perspectiva dialógica da linguagem, e vai dando provas de que o Discurso reciclado (uso da linguagem, do metaconhecimento que revela parcial aquisição de um Discurso secundário) vai sendo introduzido nos movimentos dialógicos das alunas.

Durante a análise (aula 6, 2005/1) de outro exemplar de crônica, do autor L, publicada também em jornal do estado de Santa Catarina, Renata e Beatriz evidenciam marcas de suas respectivas formaçóes letradas, quanto aos usos da linguagem em diferentes textos, como podemos comprovar com a sequência 2 .

1. A(E): Como é que o pessoal da Academia Brasileira de Letras pode concordar com uma linguagem tão errada?

2. P: Então, vão levar à risca pra outras situaçôes?

3. $A(L): A h$, não sei, mas acho que é uma fase, comigo também.

4. A (RN): Acho que é uma maneira de se expressar.

5. Beatriz: Pior se essa fase pega.

6. Renata: Se tu escreves assim legalzinho e tais tão acostumado a escrever assim, tu arrumasse um emprego que exige a tua escrita, como uma secretária, ai pra mulherada. O chefe fala pra tu redigires um texto e aí? Se eu não sei nada, se eu náo sei regra, só sei escrever daquele jeito?

7. $A(R N)$ : Eu acho que tu podes usar os dois.

8. Beatriz: Pode usar os dois. [Muitos alunos falam ao mesmo tempo.]

9. Renata: Não o texto em si. Por exemplo, uma palavra, tais acostumada usar o $X$, porque na internet se usa um monte de $x$, tu não vais saber se é pra escrever com sou com $x$.

10. $A(R N)$ : Pode confundir.

11. Beatriz: Isso é uma desculpa pra não escrever da forma correta, porque náo conhece mesmo. Dá uma disfarçada, escreve um pouco com maiúscula, com minúscula.

12. A(RN): Acho que não é proibido, quando tu tais conversando com uma pessoa que te entende [...] 
13. P: Se você recebe um e-mail de um amigo seu, usando essa linguagem, como é que você vai fazer?

14. $A(R N):$ Eu acho estranho

15. Renata: Eu tenho amigos que mandam e-mails com essas linguagens e eu respondo normal, eu não sei escrever com essa linguagem. [...] eu não gosto de escrever assim, eu não sei escrever assim. Às vezes eu não entendo algumas coisas, mas passa e nem pergunto.

16. A(RN): É porque é assim, na internet é tudo muito rápido. Então foi criado regras.

17. A(E): Nem têm regras. [Alunos falam ao mesmo tempo].

18. Renata: Tu escreves uma palavra assim hoje pra mim. Eu gostei, eu mando pra outro daqui a pouco. Não é uma regra fechada de como escrever?

19. P: Isso aí é uma linguagem tâo nova, vocês são jovens. Eu tô achando interessante a reação de vocês, eu imaginava que isso era comum pra vocês. [Refere-se à leitura e compreensão da crônica em análise] É isso aí é muito comum nos fotologs. A linguagem que se criou aí, sei lá, têm palavras que aparecem e desaparecem, outras que ficam. Bakhtin já dizia - a lingua se forma social e historicamente. [....] Qual a relação do que o autor L escreveu e os enunciados do fotolog? [silêncio na sala]. O que o autor $L$ defendeu?

20. $A(C)$ : Ele condena a linguagem.

21. P: Ele condena, ele não aceita essa linguagem. O que é que vocês pensam? 22. A(RN): É uma maneira, uma escolha.

23. Renata: Depende da ocasião. Que nem um amigo meu, que recebeu essa mensagem: sabia que ele náo entendia!

24. P: São vários tipos de linguagem. Esse modo de escrever dos jovens, o que seria isso ai pra gramática?

25. Beatriz [rapidamente]: Erro.

26. P: Existe isso pra gramática? Então pra gramática isso é erro.

27. A(RN): Acho que fizeram isso pra nem todas pessoas entenderem.

28. P: Depende da ocasião.

29. Renata: Quem é do mesmo grupo, e se entendendo tudo bem, mas fora dali, numa situação mais formal, não vai digitar um texto assim.

30. P: Vocês já tiveram a oportunidade de ouvir um texto por rádios amadores? 
31. Beatriz: É uma linguagem deles.

32. P: Exemplo: mulher é cristal. Tềm gírias especificas pra eles.

33. Renata: É isso que eu falo, isso tá entre eles. Imagina mandar essa mensagem em outro lugar.

Com foco nas intervençóes de Renata e Beatriz, ressalta-se que Beatriz deixa revelar suas concepçóes restritas de linguagem, segundo intervençóes 5 e 11, quando aponta como erro a variaçáo linguística que aparece na leitura de um exemplar do gênero. Em resposta e na direção de desenvolver o metaconhecimento, o professor, com movimentos contrastivos sutis à aluna, explica o fenômeno da variaçáo linguística (intervençóes 13, 19, 28, 30). Beatriz, percebendo que os dizeres de Renata são apoiados pelo professor e que este refuta a opiniáo dela sobre o erro, adere parcialmente (intervençáo 31 ) ao posicionamento de Renata no decorrer das interaçóes. Beatriz, dessa forma, usa movimentos exemplificativos e confirmativos a Renata, para indicar inicial compreensão de que a linguagem vai se adequando às situaçôes enunciativas. Essa mudança de posicionamento de Beatriz exemplifica a percepção dela sobre a não produtividade em repetir modelos e em permanecer fechada em conceitos reproduzidos, sem reflexão, em experiências anteriores com a linguagem.

Após a leitura de exemplares do gênero, com o intuito de instigar posterior escrita, o professor, na aula 3 de 2005/1, propóe a produção da crônica como o primeiro texto do ano. Na exposiçáo oral dessa proposta, os pontos de reflexão são o assunto e uma característica particular do gênero: a ironia. Náo surpreendentemente, o contato inicial com características heterogêneas do gênero faz com que vários movimentos indagatórios e até contrastivos à proposta do professor sejam externados por alunos de Letras, incluindo Renata e Beatriz:

\section{(3)}

1. $P$ O que vocês acham de escrever uma crônica?

2. $A(S)$ : Dificil.

3. P: Dificil?

4. Renata: Podemos falar mais de quem? Do professor? 
5. P: Tem que pensar num fato cotidiano, que se possa ironizar e ao mesmo tempo a pessoa ler, entender. Qual é o objetivo para o meu texto? Para quem? $O$ autor $M$ escreveu para aqueles que estavam de saco cheio da música [...]

6. P: Se é uma coisa que incomoda só um, o leitor não vai entender, né?

7. Renata: Um incômodo entre pai e filho pode ser entendido por gente de fora porque é algo comum.

8. Beatriz: É como ali na frente, a gente chega e nunca tem espaço pra moto, então hoje eu pensei, tá chovendo e vai ter espaço pra mim e tinha um carro bem comprido ocupando o lugar das motos. E o que é que fazem esses caras da guarita?

9. P: Você quase já fez uma crônica agora.

Como exemplifica essa sequência (3) de interações orais em sala, as alunas Renata e Beatriz, por meio de movimentos exemplificativos (intervenções 4, 7 e 8), indicam suas reaçōes-resposta a situaçôes reais de enunciação, as quais conhecem, e que podem funcionar como assuntos nas crônicas. As duas são apoiadas pelo professor e Beatriz é explicitamente elogiada, na intervenção 9, após narrar uma problemática da universidade.

Após a produção escrita de exemplares desse gênero pelos alunos, a leitura de crônicas entra novamente como atividade em sala de aula. Por conseguinte, o professor seleciona exemplares de crônicas dos alunos, a fim de realizar a análise linguística dos textos e de dar suporte à reescrita, ou seja, ao aprimoramento do texto, em termos discursivos, textuais e gramaticais.

\section{Leitura e análise linguística de crônicas: um caminho para reescrita}

A produção da crônica de Renata (Anexo 1), intitulada $B+a=B a$, $B+e=B e, B+i=B i, B+o=B o, B+u=\underline{B U R A C O}$, é escolhida pelo professor para a análise linguística, ou seja, para desenvolver reflexôes sobre os usos da língua neste gênero. Em acréscimo, o professor, na interação constante com os alunos, propóe encaminhamentos para a reescrita da crônica de Renata, dando suporte, assim, a ela e aos demais alunos na atividade de reescrita do texto. Dessa forma, esse tipo de atividade representa um momento desencadeador da ampliação do metaconhecimento relativo à composição do gênero crônica. 
Os alunos têm oportunidade de externar suas experiências, conhecimentos prévios e atuais, sendo valorizados como corresponsáveis em práticas situadas de linguagem. Nessa perspectiva, por mais sutis que pareçam ser as transformaçóes, em Eventos reflexivo-transformativos, aos olhos dos que estejam distantes deste processo, elas estão sendo apresentadas e discutidas como evidências de práticas situadas de letramento, as quais instigam e desafiam Renata e Beatriz, neste caso sob análise, a açóes mais colaborativas e significativas com a língua, como se pode comprovar com a sequência (4).

1. P: Então vamos lá pro texto do BURACO. [referindo à crônica elaborada por Renata] Vamos seguir o mesmo roteiro das perguntinhas que vocês têm. [...] Pensem nessas questóes e depois váo falando. [Tempo para leitura] Falaram ai que é uma crônica. Por quêe? [alunos conversam entre si] Ou é uma anedota?

2. Beatriz: O que é uma anedota?

3. P: Uma piada?

4. P: Lembram naquele texto do autor $M$, uma crônica, usa ironia e trata de um fato do dia a dia. Quem escreveu isso dai, escreveu pra quem? [alunos conversam muito entre si] [...]

5. $A(C)$ : Motoristas.

6. P: Órgãos públicos, né? O que mais, o que gerou esse texto?

7. A(E): Com certeza um monte de buraco perto da casa dela, estragou o carro dela.

8. $A(S)$ : É buraco pela cidade, em todo lugar.

9. P: Voltando. O leitor desta cidade vai se identificar com essa crônica. [...]

10. Beatriz: Ainda mais quando fala da casquinha de sorvete.

11. P: Outro detalhe: quais são os argumentos da crônica que o autor usa para chamar a atenção do leitor? Quais as expressóes, o texto todo é irônico, que indicam ironia?

O aspecto discursivo, especialmente o temático, do gênero crônica impulsiona as interaçóes iniciais na leitura de texto elaborado em Letras, o que oportuniza aos alunos realizarem várias intervençóes, como as de Beatriz em (2) e (10), por meio de movimentos indagatórios e confirmativos ao professor. 
Durante a leitura e respectivas análises da crônica de Renata (sequência 5, a seguir), os movimentos mais intensos do professor e dos colegas de Renata são os confirmativos, na direção das escolhas realizadas por ela, sempre acrescidos de justificativas aos argumentos apresentados no texto. Durante as intervenções, Renata expóe lembranças de leitura (intervenção 4) e da produção de textos na Educação Básica, complementa dizeres do professor sobre vozes presentes no texto (intervenção 12) e indica sua incerteza sobre o uso de vírgulas e sobre a elaboração de parágrafos.

1. P: Mas vocês lembram de ter estudado figuras de linguagem no Ensino Médio? Comparação, metáfora... uma lista.

2. $A(R N)$ : A única coisa que o professor fazia era só ler o texto e responder exercícios.

3. P: Autor principal, secundário...

4. Renata: Não, era só interpretação de texto mesmo.

5. Beatriz: O que o autor quis dizer, interprete com suas palavras.

6. $P$ : Tá, o que vocês acharam de irônico aí?

7. $A(C)$ : "Tudo em nome do progresso".

8. P: $O$ que mais? Titulo? Por que o autor colocou assim, $B+a=B a, B+e=B e$, $B+i=B i$.

9. Beatriz: Lembra aquela musiquinha do Biotônico Fontoura.

10. P: Tem muita coisa que dá pra tirar do título. Pode ser uma ironia.

11. A(E): Algo tão simples como o be-a-bá e não arrumam os buracos. Também indica uma burocracia [...]

12. Renata: Isso acontece muito na secretaria de obras da prefeitura.

Analisando juntamente as sequências (4) e (5), depreende-se que Beatriz, na condição de moradora da cidade indicada por Renata na crônica, realiza um movimento confirmativo (intervenção 13, da sequência 4) aos dizeres do professor. Esta aluna expóe sua compreensão quanto ao assunto abordado no texto em análise e quanto à repetição intencional do termo buracos feita pela colega. Beatriz também confirma, na intervenção 
5 (sequência 5), o dizer de Renata, quanto às lembranças da escolarização básica e realiza movimentos exemplificativos, com vozes advindas de novela e de outro programa televisivo, para justificar as falas de políticos sobre o problema enfocado no texto. O professor, nesse evento de leitura e análise da crônica de Renata, tece elogios a esta aluna em dois momentos: $o$ texto está bem fundamentado ironicamente; esse texto não tem problema de coesão $e$ coerência. Estes elogios, por sua vez, comprovam um determinado controle da aluna na elaboração textual, bem como reforçam a afinidade dela com o uso da ironia - marca característica da crônica.

Outro exemplo de análise linguística recebe destaque com o enfoque dado à crônica (Anexo 2) de uma aluna da sala (Sandra), em que Renata e Beatriz também marcam presença nas interaçóes.

1. P: Aqui tem um texto da Sandra. Que texto é esse dai?

2. $A(A)$ : Crônica

3. P: Vocês já leram?

4. $A(A)$ : Metade.

5. Renata: Também recebi esse e-mail Sandra, coitada das empregadas.

6. P: Isso aqui é o e-mail que você recebeu contando.

7. Sandra: É, isso aqui é o e-mail, posso até trazer pra mostrar, sobre a empregada...

8. P: Sim, e você incluiu aqui no texto. É original que colocasse aqui em partes do texto.

9. Renata: É, fala de um monte de coisas.

10. P: Primeiro vamos ver que texto é: crônica, artigo, conto.

Depois, quero que vocês façam um levantamento, do texto da Sandra, né, de problemas que por acaso vocês encontrem no texto. [...] Podem dar uma olhadinha nesse modelo que entreguei aqui pra vocês. A textualidade, a questão da escrita. Vejam se vocês conseguem captar algo ali. [tempo para leitura e análise] O que é "ria"? Qual classe de palavra?

11. A: Verbo

12. P: Morfologicamente, pela análise morfológica é verbo. E o se é o que?[...] 
13. P: Já que nós estamos vendo a questão da textualidade, algumas questóes gramaticais, isso tudo é pra aprendizagem, então, "Ria, se puder", ali pode colocar dois pontos.

14. Renata: Mas pode continuar essa vírgula?

15. P: Sim, é como no título.

16. P: Esse texto tem algum problema ortográfico? [silêncio]

17. A(E): Comenta de uma letra em minúsculo, que deveria estar em maiúsculo.

18. Beatriz: Ali na parte "pensei, se tratar de um desabafo", acho que não vai uma virgula.

Mas é pensei se tratar ou "pensei tratar-se"?

19. Sandra: "Pensei em se tratar de um desabafo".

Renata, na sequência (6), manifesta-se em vários momentos, com objetivos diversos:

- apoiar Sandra, no início, através de movimento confirmativo a ela, indicando ter conhecimento do e-mail que desencadeou a crônica (intervençóes 5 e 9);

- realizar movimentos indagatórios ao professor, a fim de confirmar ocorrências em análise (intervenção 14);

- demonstrar incerteza quanto a determinado item enfocado;

- opor-se a Sandra, através de movimento confirmativo ao propósito do professor quanto à realização da análise linguística do texto dela (intervenção 18).

Beatriz, por sua vez, realiza movimentos de confirmação ao professor quanto às ocorrências em análise, os nomeados problemas do texto.

De outra forma, em dado momento, Beatriz procura apoiar a colega Sandra, utilizando um movimento metalinguístico que representa, nesse caso, uma marca do Discurso reciclado, por meio da metalinguagem já adotada pelo professor, como se acompanha com a seguinte sequência:

1. Beatriz: Pode usar "ignorando-a".

2. P: Pode ser, você vai usar um anafórico, que está lá. Por que você vai usar "ignorando-a"? 


\section{Beatriz: Por que é a empregada. É uma questáo de coesáo, torna o texto coerente e coeso ao mesmo tempo.}

Beatriz, ao sugerir, na intervenção 1, uma outra forma linguística para a escrita de Sandra, tenta convencer o professor de que o referente do anafórico (pronome oblíquo a) é a empregada (intervenção 3), o que possibilita dar coesáo e coerência ao texto. No fechamento das discussões, da mesma forma que Renata o faz durante a análise da crônica por ela produzida, Beatriz realiza um movimento avaliativo, apoiando as reflexóes conduzidas pelo professor. Ela reafirma que as orientaçóes do professor possibilitam compreender o que é uma crônica, como é possível produzila, a fim de não apenas reproduzir modelos, conforme direcionado no período escolar.

A partir dessas explanaçôes sobre a atividade de análise linguística da crônica de Sandra, na comparação com a de Renata, comprova-se que o professor adota posicionamentos diferentes. $\mathrm{O}$ motivo pode ser o conhecimento ampliado, advindo da análise do texto de Sandra (atividade que acontece anteriormente à análise da crônica de Renata), sobre as possíveis reaçóes-resposta dessas alunas na atividade.

Com a análise da crônica $B U R A C O$, de Renata, o professor inicia as discussóes, sugerindo que os alunos sigam um roteiro de análise e não que façam um levantamento dos problemas do texto. Ainda, o professor dá saliência aos elementos do gênero discursivo, como ironia e correspondentes escolhas linguísticas, que denotam essa característica da crônica de Renata. Com a crônica de Sandra, por outro lado, a ênfase coloca-se nos aspectos gramaticais, compreendidos por ela como erros. Logo, reflexóes sobre o uso da língua, em muitas ocasióes, caminham em paralelo a muitos conflitos. Estes se manifestam ora pelo desconhecimento da função e dos sentidos da atividade, ora pela forma como se dão as interaçóes nos eventos orais, os quais expóem os alunos às análises, compreendidas como julgamentos por alguns alunos, em vista da linguagem norteadora das discussóes.

Em síntese, nessa complexa dinâmica de realizar leituras sobre o gênero crônica e reflexóes sobre a língua, com o intuito de implementar percepçóes, posicionamentos e formas de oralidade, leitura e escrita, professor e alunos vão se constituindo sujeitos letrados em práticas acadêmicas de letramento. Movimentos diferenciados predominam em eventos de natureza diversa 
com o gênero crônica. Nas análises de exemplares do gênero, prevalecem os movimentos exemplificativos, reforçando marcas da escolarização básica, e movimentos contrastivos às discussóes sobre variação linguística e recursos estilísticos do gênero, os quais são dados novos, mencionados por meio de uma metalinguagem também própria da teoria dos gêneros discursivos. Nas análises de crônicas produzidas pelas alunas Renata e Sandra, predominam movimentos constrastivos e confirmativos ao professor e às autoras dos textos.

Se ainda forem considerados os depoimentos de Renata e Beatriz, ao final de 2006, constata-se que as reaçôes-resposta às orientaçóes do letramento com o gênero discursivo crônica não são sempre imediatas, como se aborda na seção que segue. Essas reaçóes podem ser nomeadas como reaçóes-resposta retardadas (BAKHTIN, 2003), que comprovam a ocorrência de práticas reflexivas e transformativas em um continuum de implementaçóes e a constituição gradativa da identidade das alunas no domínio acadêmico.

Portanto, movimentos dialógicos vão delineando-se de modo particular em situaçóes enunciativas também singulares, ou seja, em Eventos reflexivo-transformativos de natureza distinta, através de leituras diversas do gênero crônica.

\section{Para além do letramento acadêmico: outras leituras e novos posicionamentos}

$\mathrm{Na}$ relação com outros contextos sociais, o letramento acadêmico auxilia Renata a avaliar seu próprio agir, a analisar as situaçóes profissionais, no contato com açóes de amigos (círculo pessoal) e de colegas de trabalho. O depoimento (1), ao final de 2006, é central como indicador das transformaçóes identitárias e do uso do letramento crítico.

(1) Às vezes é engraçado, a gente conversa com pessoas de fora, com amigos que leram a mesma coisa que tu leu, eles ficam falando sobre aquilo e a gente fica pensando "nossa, até pouco tempo atrás eu também tinha esse pensamento". Hoje a gente vê com outros olhos. Tu lês umas matérias, acaba discutindo com a pessoa, mas ela diz "tais doido, ele não quis dizer isso, não, mas olha e pensa". Mas eles não têm esse conbecimento. Já me peguei algumas vezes, com alguns amigos que acabaram lendo as mesmas coisas, que a gente já viu com outros 
olhos, além do que o texto queria, e eles não, só ali focados naquela coisa. [...] O legal disso tudo é pôr a teoria na prática sem dizer pro outro que isso é teoria. (RENATA, 2006)

Renata, nesses dizeres em (1), sinaliza o valor do metaconhecimento construído em Letras. Ela deixa claro que o uso do letramento crítico a faz (re)contextualizar as orientaçóes de letramento do contexto acadêmico na interação com os amigos, mesmo sem utilizar a metalinguagem especializada. Essas satisfaçóes externadas por Renata lhe concedem um status ampliado de pessoa, com um capital cultural diferenciado de outros que a rodeiam. Renata acrescenta a essas explicaçóes que a transferência de conhecimentos para a família também acontece, pois consegue repassá-los na educação da filha e no melhoramento da visáo do marido.

Os benefícios da leitura situada do gênero crônica, quando da análise linguística do próprio texto produzido, sáo marcados na fala de Renata, também ao final do ano de 2006.

(2) Do gênero a gente consegue captar [...]. No começo isso era muito difícil, não sei se tu lembras, né, com o professor Tiago. Nossa! Escrevia uma crônica, o professor dizia "é um artigo". Hoje a gente relê os textos da gente, a gente olha e realmente diz "isso é uma crônica". Não sei se tu lembras do texto do Buraco, que eu escrevi [...]. Escrevi como um artigo, era um artigo, ninguém me tirava da cabeça que aquilo era um artigo e era uma crônica. Eu tava lá fazendo um artigo e era uma crônica e nem imaginava. Eu reli ele outro dia e disse "nossa, toda a composiçáo de uma crônica tá aqui, e pra mim era um verdadeiro artigo". Naquela época, bem no comecinho, eu também escrevia por escrever, náo parava muito pra pensar, né. Escrevia o que vinha na minha cabeça, tava lá a idéia. (RENATA, 2006)

Este depoimento (2) de Renata traz uma evidência de que o metaconhecimento da língua com o gênero crônica é ampliado e torna-se mais significativo para ela, em um tempo posterior às aulas do professor Tiago. A reação-resposta retardada comprova que, diante da necessidade de cumprir as propostas sugeridas pelo professor Tiago, para produzir um número determinado de textos no semestre, Renata procurou adequar-se e utilizar o metaconhecimento que tinha naquele momento. O Discurso reciclado funcionou como o suporte para que ela elaborasse a crônica nos 
moldes discutidos e constitutivos do gênero em enfoque no curso de Letras. É com o olhar distanciado ou com uma outra leitura dirigida à produção escrita intitulada BURACO que, com apoio do metaconhecimento sobre o gênero, Renata reconhece e afirma ser uma crônica o texto elaborado por ela. Nesse ponto, justifica afirmar que o letramento é um processo sóciohistórico-cultural em contínua construção, através do qual os sentidos vão se constituindo, como também vão constituindo os sujeitos letrados em um emaranhado conjunto de atividades que vão (re)contextualizando as experiências de cada um.

Outra mudança em Renata, oriunda do trabalho direcionado pelo professor Tiago, é o ler nas entrelinhas, conforme indicado por ela:

(3) Então com as aulas do professor Tiago a gente teve toda uma outra visão, todo um novo olhar, a questão dos gêneros, na verdade a gente lia, mas não entendia. Não que não entendia, mas é que no $2^{\circ}$ grau a gente não tinha o incentivo, a gente só ficava na leitura, a gente não interpretava, a gente náo lia as entrelinhas. Hoje em dia a gente pega um texto na mão e lê com outros olhares, tu para numa palavra chave, vê que não é só aquilo que tá escrito, isso quer dizer algo a mais. (RENATA, 2006).

Como se verifica com esse dizer em (3), Renata expressa a valorização pela oportunidade de ampliar sua compreensão das relaçóes de poder subjacentes aos textos. Logo, a orientação crítica do letramento, realizada pelo professor Tiago, é intensamente indicada por ela como produtiva a sua constituição letrada mais reflexiva no âmbito acadêmico e em outros contextos como o familiar e o profissional.

No tocante aos dizeres da aluna Beatriz, em entrevista no final de 2006, há destaque para o decisivo diferencial da interação construída entre o professor Tiago e os alunos de Letras, o que viabilizava maior confiança nas tomadas de decisão e, por consequência, maiores oportunidades de transformação nas práticas de escrita:

(4) Assim, hoje os professores pedem resenhas, pedem diferentes gêneros pra produzir, nem sempre dizem como é, pressupóem que a gente já saiba. Só falam, mas como fazer, a gente tem que correr atrás. A gente estudou alguns gêneros, e os outros a gente vai ter que correr atrás, né. [...] Pedir pra fazer produção 
textual, dá dicas, mais ou menos algumas características, pedir pra gente produzir, depois ter aquela correçáo que volta pra ti pra ver o teu erro, e explicar através do nosso próprio texto. Isso eu acho que faz bastante falta na nossa faculdade, na nossa formaçáo, porque teve naquele tempo, depois tudo que é ensinado, as matérias novas, as disciplinas, náo sâo em cima de textos, e ali a gramática explicada em cima de texto. [...] Eu sinto falta, entáo, dessa aula. Não é só apontar o erro que você fez, tem que mostrar o outro caminho, por que é que náo pode ser daquele jeito. Antes a gente tinba esse apoio, agora a gente não tem mais. (BEATRIZ, 2006).

Com esse depoimento (4), há um ano distanciada das aulas do professor Tiago, Beatriz reforça o valor atribuído por ela à aprendizagem colaborativa, como a leitura situada e a análise linguística do texto produzido, que a fez refletir e encontrar outros caminhos na implementação qualitativa dos textos. Também se pode depreender que as reflexóes com a língua, instigadas nas aulas do professor Tiago, representam uma prática transformada, aos olhos dela, que, paulatinamente, estavam dando subsídios para uma prática transformadora, ou seja, uma prática mais consciente na elaboração linguístico-enunciativa.

Ao mesmo tempo em que Beatriz deixa revelar aspectos positivos, quanto a sua participação em Letras, enfatiza sua insatisfação com orientaçóes de alguns professores no curso, implicitamente comparadas com as do professor Tiago, por meio de um discurso contestador e resistente. Nesse discurso emerge sua posição, no momento atual da entrevista, como professora na Educação Básica. O que é particular nos dizeres de Beatriz é o uso do letramento crítico, referente à interface pretendida por ela entre os Discursos acadêmicos em Letras e dos Discursos escolares da Educação Básica, onde exerce função profissional. Como comprovação desse posicionamento contestador de Beatriz, eis um depoimento:

(5) Se você faz [análise linguística, em conjunto, dos textos produzidos pelos alunos] com aquele monte de aluno, ai tem o teu tempo em casa. Tem que fazer alguns recortes, porque não dá pra colocar tudo em transparência. Não dá pra mostrar pra todo mundo. Tem que achar o que o amiguinho errou ali: "Tente achar, qual o defeito da frase." Vou ter que fazer um recorte nos textos, e náo 


\section{seria o ideal, né. Deveria mostrar o texto inteiro.(BEATRIZ, 2006)}

O metaconhecimento mostra-se como o grande aliado nos dizeres de Beatriz, dando a ela mais suporte nas suas argumentaçóes e no uso do letramento crítico. No exemplo (5), expóe limitaçóes para desenvolver uma atividade marcante nas aulas do professor Tiago: a análise linguística dos textos produzidos pelos alunos. Dessa forma, há uma adesão tanto à prática de análise linguística de textos de alunos, orientada pelo professor Tiago, quanto aos dizeres deste profissional, quando afirmava ser bastante desafiante a realização de um trabalho dialógico com a linguagem nas escolas. Ainda, ao afirmar que o recorte nos textos, para proceder com a atividade, não seria $o$ ideal e que deveria mostrar o texto inteiro, Beatriz denota uma reação-resposta ao já-dito, bem como ao pós-dito, como se ela pudesse antecipar dizeres do professor Tiago diante das decisóes realizadas por ela na escola.

O olhar de Beatriz, então, mais que retrospectivo, é prospectivo, no sentido de predizer o que julga como adequado para expandir sua identidade como professora da Educação Básica. A posição questionadora e, por vezes, contestadora, já nas aulas do professor Tiago, é intensificada por ela, ao final de 2006, quando da entrevista realizada, em virtude da identidade assumida como professora.

\section{A construção de letramentos: considerações finais}

O construto singular a que se chega, com base nas análises realizadas, é que o trabalho com a língua nas duas disciplinas em questão, e os consequentes modos de constituição letrada de Renata e Beatriz, inserem-se no modelo dialógico dos letramentos acadêmicos (FISCHER, 2007). Essa conceituação é inspirada nas abordagens de Lea e Street (2007), os quais apontam o modelo dos letramentos acadêmicos como o mais adequado para se discutir a produção de alunos e o fenômeno do letramento em contextos acadêmicos. Esse modelo engloba questóes como a construção de sentidos, as identidades socialmente situadas, as relaçôes de poder e de autoridade que subjazem às práticas de letramento nos contextos acadêmicos. Em acréscimo ao que expóem Lea e Street (2007), propóe-se a existência de um modelo dialógico dos letramentos acadêmicos como norteador da constituição letrada dos alunos ingressos em Letras em 2005. A justificativa para essa proposição 
é a ocorrência de práticas de letramento em que o gênero discursivo, no caso, a crônica, funciona como mediador das complexas relaçóes interacionais de sala de aula. Por consequência, são desencadeadas relações dialógicas entre os sujeitos participantes das aulas.

Nesse processo dinâmico e dialógico de trabalho com o gênero crônica, movimentos dialógicos de Renata e Beatriz, no interior dos Eventos reflexivo-transformativos, possibilitam inferir como elas se constituem sujeitos letrados. Em virtude da ocorrência desse tipo de evento é que se dá a construção de um dos três ${ }^{6}$ tipos de letramento acadêmico que integram este modelo: o letramento reflexivo-transformativo. Este tipo de letramento permite a Renata, a Beatriz e a outros alunos de Letras, participantes da pesquisa conduzida em 2005 neste curso, desenvolver o controle no uso de Discursos secundários e da metalinguagem que os constituem, seja por meio do Discurso reciclado e/ou do uso dos letramentos críticos, com o propósito de transformação de práticas e identidades sociais.

O uso do Discurso reciclado é ampliado, através da capacitação crítica, na direção do uso dos letramentos críticos, por ocorrência de um maior domínio do metaconhecimento que integra os Discursos dominantes. Assim, Renata, Beatriz e outros alunos de Letras, para além de se adaptarem a determinados eventos de letramento, passam a fazer análises mais criteriosas, reflexivas e críticas dos Discursos primários e secundários. $\mathrm{O}$ uso dos letramentos críticos, especialmente do letramento reflexivo-transformativo, é presenciado nas aulas do professor Tiago. Esse tipo de letramento faz-se notar por meio das intervençóes de Renata e Beatriz, seja na leitura situada de exemplares de crônicas ou nas análises linguísticas desse gênero. Essas alunas passam a fazer escolhas próprias, tanto na oralidade quanto na escrita, distanciando-se do gênero balizador e do Discurso reciclado.

Portanto, os movimentos realizados por Renata e Beatriz seguem um percurso evolutivo e qualitativo, porém não linear, que vai do discurso do déficit de letramento, passando pelo uso do Discurso reciclado e chegando ao uso crítico dos letramentos, incluindo o reflexivo-transformativo. Esse percurso reforça que os letramentos acadêmicos são caracterizados como dominantes (GEE, 1999). Por esse motivo é que se visualiza o empenho de Renata e Beatriz, por se inserirem como coparticipantes no 
contexto acadêmico e posteriormente em outros contextos sociais, os quais representam instituiçóes de poder na sociedade que suportam práticas de letramento também dominantes. Nesse sentido, para serem reconhecidas como membros ativos nessas práticas, Renata e Beatriz deixam marcas que visam à expansão das formas de ser, agir, interagir, falar, ler, escrever e usar artefatos culturais que concedam mais status, poder e identidade nos contextos sociais dos quais passam a participar.

\section{Notas}

1 Esta é uma versão revisada e ampliada de trabalho apresentado, pelas autoras, no I Fórum Ibero-Americano de Literacias (FIAL), realizado em julho de 2009 em Braga, Portugal.

2 Segundo Gee (2001), Discursos com “D” maiúsculo diferencia-se de discursos com "d" minúsculo. Para este autor, discurso significa apenas a linguagem em uso, diferentemente de Discursos, que ultrapassam o escopo de uso da linguagem.

3 Dados presentes neste trabalho advêm de pesquisa de doutorado de Adriana Fischer, desenvolvida de 2004 a 2007, no Brasil, sob orientação da Doutora Nilcéa Lemos Pelandré, na UFSC, e em Portugal, no doutorado sanduíche, sob orientação da Doutora Maria de Lourdes Dionísio, na Universidade do Minho, com apoio da Capes e do Programa de Pós-Graduação em Linguística da UFSC.

4 P simboliza professor. O nome Tiago é fictício, bem como o das alunassujeito da pesquisa.

5 Iniciais do nome de um(a) aluno(a).

6 Os três tipos de letramentos acadêmicos, elaborados por Fischer (2007), são: letramento interDiscursivo, identitário-profissional e reflexivotransformativo. 


\section{REFERÊNCIAS}

ANDRÉ, Marli. Etnografia na prática escolar. 9. ed. Campinas, SP: Papirus, 2003.

BAKHTIN, Mikhail. Os gêneros do discurso. In: . Estética da criação verbal. 4. ed. São Paulo: Martins Fontes, 2003. p. 261-306. BOIARSKY, Carolyn R.; HAGEMANN, Julie; BURDAN, Judith. Working class students in the academy: who are they? In: BOIARSKY, Carolyn R. (Org.). Academic literacy in the English classroom: helping underprepared and working class students succeed in college. Portsmouth: Boynton/Cook Publishers, 2003. p. 1-21.

DIONÍSIO, Maria de Lourdes. Educação e literacias. Relatório para professor associado do grupo disciplinar de Metodologias da Educação, do Instituto de Educação e Psicologia da Universidade do Minho. Braga, Portugal, 2006. 121 p. Disponível em: <http://www.ucpel.tche.br/poslet/ ementas/topicos_letramento_leitura.php>.

FISCHER, Adriana. A construção de letramentos na esfera acadêmica. 2007. 340 f. Tese (Doutorado em Linguística) - Programa de PósGraduação em Linguística, Centro de Comunicação e Expressão, Universidade Federal de Santa Catarina, Florianópolis, 2007.

GEE, James Paul. Reading as situated language: a sociocognitive perspective. Journal of adolescent \& adult literacy, Newark Delaware, v. 44, n. 8, p. 714-725, may 2001.

. The new literacy studies: from 'socially situated' to the work of the social. In: BARTON, David; HAMILTON, Mary; IVANIC, Roz. Situated literacies: reading and writing in context. London: Routledge, 2000. p. 180-196.

GEE, James Paul. Social linguistics and literacies: ideology in discourses. 2. ed. London: The Farmer Press, 1999.

HALL, Kathy. Co-constructing subjectivities and knowledge in literacy class: an ethnographic-sociocultural perspective. Leeds, UK, v.16, n. 2, p. 178194, sept. 2002. Disponível em: <http://www.channelviewpublications.net/ le/016/0178/le0160178.pdf> Acesso em: 30 nov. 2005. 
LANKSHEAR, Colin et al. Introduction. In: . Changing

literacies. Philadelphia: Open University Press, 2002. p. 1-7.

LEA, Mary R.; STREET, Brian V. The "academic literacies" model: theory and applications. In: SIMPÓSIO INTERNACIONAL DE ESTUDO DOS GÊNEROS TEXTUAIS(SIGET), 4., 2007, Tubarão. Anais... Tubarão: Unisul, 2007. p. 227-236. 1 CD-ROM.

SOARES, Magda B. Pesquisa em Educação no Brasil - continuidades e mudanças: um caso exemplar: a pesquisa sobre alfabetização. Perspectiva: Revista do Centro de Ciências da Educação, Florianópolis, v. 24, n. 2, p. 393-417, jul./dez. 2006.

. Novas práticas de leitura e escrita: letramento na cibercultura.

Educação e sociedade, Campinas, v. 23, n. 81, p. 143-160, dez. 2002. Disponível em: <http://www.cedes.unicamp.br>. Acesso em: 3 nov. 2004.

STREET, Brian. Academic literacies approaches to genre? In: SIMPÓSIO INTERNACIONAL DE ESTUDO DOS GÊNEROS TEXTUAIS (SIGET), 5., 2009, Caxias do Sul. Anais... Tubarão: Unisul, 2009. Disponível em: <http://www.ucs.br/ucs/extensao/agenda/eventos/ vsiget/portugues/anais/textos_autor> Acesso em: 28 set. 2009. 


\title{
ANEXO 1 - Crônica de Renata
}

\author{
Curso de Letras - $1^{\mathrm{a}}$ Fase
}

$\mathrm{B}+\mathrm{a}=\mathrm{Ba}, \mathrm{B}+\mathrm{C}=\mathrm{Be}, \mathrm{B}+\mathrm{i}=\mathrm{Bi}, \mathrm{B}+\mathrm{o}=\mathrm{Bo}, \mathrm{B}+\mathrm{u}=\underline{\mathrm{BURACO}}$

Circulando recentemente pelas ruas de nossa cidade pude observar várias coisas acontecendo.

Uma, a cidade cresceu e está crescendo muito rápido;

Outra, existem muitas obras, muitas construçöes e muita gente;

Mais outra, existem muitos, muitos mesmo, BURACOS.

Não conseguimos andar muito sem que lá esteja um de nossos velhos conhecidos: o buraco.

Parece impossivel sair de um sem logo logo, cairmos em outro. A impressão que às vezes temos é que por debaixo das estradas existem aqueles bichinhos de desenho animado, que cavocam e escavam tudo até que, ele apareça de novo: O Buraco.

É buraco na zona rural, é buraco na cidade, é buraco em tudo que é lugar, parece uma perigosa e contagiosa epidemia que está em toda parte.

Tudo em nome do Progresso.

Ah! O progresso... Piorou. Construção começando e podemos esperar que não muito longe um buraco surgirá. É para ligação de água, ligação de esgoto e sei mais o que.

O buraco aparece e não desaparece, mas reaparece todo dia cada vez maior e mais profundo, porque os responsáveis não se preocupam, não se importam, com o que um simples buraquinho pode causar.

É reclamação daqui, é publicação de lá e nada, porque a "Gente Grande", o "Peixe Graúdo", só se importa com obras tamanhas, de repercussão rápida entre o poyo, que aliás, se ilude muito fácil.

É só falar em asfalto, e aí se acaba tudo, esquecem de tudo. Só ouvimos o comentários "- Ah! A tão sonhada pavimentação chegou.", "- A modernidade bateu em nossa porta.", "- Ai, poeira vai acabar.", doce ilusão.

Primeiro, a poeira que era amarela, agora será preta;

Segundo, vem o não planejamento de água e esgoto para se fazer o asfalto e logo depois: o buraco;

Terceiro, vem aquela camada generosa do material que mais parece casquinha de sorvete e em seguida: o buraco;

Por fim, depois de alguns dias de uso chega todo sorridente, nada mais nada menos que: o nosso amigo BURACO.

E buraco meu amigo, "ninguém" vê, "ninguém" se preocupa, mas todos, como eu e você, se incomodam e muito.

Ete foi analiodo coletivannente. 


\title{
ANEXO 2 - Crônica de Sandra
}

\author{
Ria, se concordar
}

Há cerca de uma semana, chegou um e-mail dizendo assim: Ria, se puder:Diário de uma doméstica.

pensei, se tratar de um desabafo de uma empregada doméstica, era, mais ou menos isso, o texto falava de uma empregada, que não entendia muitas coisas, o texto ignorava e ironizava as empregadas, o texto mais ou menos falava assim:

- Creusa pega o telefone e fofoca com a amiga Craudete:

- Cé num sabe de úrtima? Eu descobri que aqui nessa mansão que eu trabaio é tudo fachada!

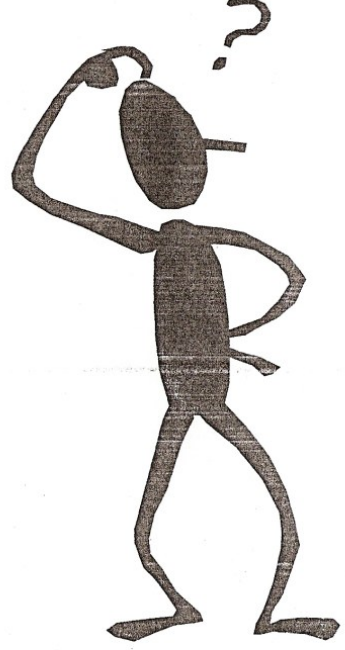

-Que nada, fia...é piquininho de da dó! AAchei um absurdo um texto falando sobre tantas coisas, que todos nós sabemos,o que) inclusive as domésticas, achei um atrevimento, pois o texto todo foi escrito com palavras erradas, insinuando que nem escrever elas sabem .

Foi um texto com humor ridículo, sem nenhuma consideração com as pessoas que estão numa classe social menos favorecidas não achei graça nenhuma, e acho também que quem escreveu, deve fazer parte de uma classe, que pode ter dinheiro mas nenhuma educação.

Pois criticou as

- pergunta a colega confusa.

-Nada aqui é dos patrão! tudo é imprestado! tudo! tudo! Cê cridita numa coisa dessas? Oia só: a ropa que o patrão usa é deim tal de Pierre Cardan, o carro é do tal de mercedes.

- Nossa que pobreza!

- E além de pobre, eles são muito ixibidos! Imagina que ôtro dia eu escutei o patrão no telefone falano que tinha. pessoas apontando-as como ignorantes sem nem mesmo pensar, que poderia estar escrevendo um texto com humor ridiculo.E não foi tão genial quanto imaginou, pois poúeria ter feito um texto com mais criatividade mais engraçado sem ter passado tantos dos limites. um Picasso...

-E num tem? 


\section{Academic literacy and the construction of meanings within a gender reading}

\section{Abstract}

The current study aims to characterize how different ways of reading within a discursive genre contributes towards students considering themselves insiders in an academic context. The analyzed data were collected during 2005 and 2006 in a Brazilian undergraduate course through participant observations and oral interviews. These data are part of the so called reflexive-transformative events, including reading, production and linguistic analysis of the journalistic chronicle discursive genre. Those events also integrate the dialogic model of the academic literacies which refers to the construction of meaning, identity, power, authority and to the institutional nature of what is considered to be knowledge in the context of a Language and Literature academic course. Since a longitudinal process with reading is carried out, data of two female undergraduates, related to the chronicle genre in two disciplines of the course are discussed. Results show that (1) knowing the operation a of certain social field data, of which the genre destined to reading and writing production makes part, and (2) developing the meta-knowledge that constitutes it, are power tools for the above-mentioned students. In fact, they employ critical literacy and the dominant literacies to which they

\section{Literacidad académica y la construcción de sentido con la lectura de un género}

\section{Resumen}

El objetivo de este trabajo es caracterizar como las diferentes maneras de lectura situadas de un género discursivo contribuyen para que los estudiantes puedan tener información privilegiada en el contexto académico. Los datos fueron recogidos en 2005 y 2006 en un curso de magisterio de la enseńanza superior en Brasil, mediante observaciones participante y entrevistas orales. Estos datos son parte de las concepciones llamadas reflexivas-informativas, que incluyen la lectura, lectura, la producción y el análisis lingüístico del discurso de género periodístico. También integran el modelo dialógico de las literacidades académicas, que se refieren a la construcción de sentido, a la identidad, al poder, a la autoridad y a la naturaleza institucional lo que cuenta como conocimiento en el contexto de un curso de Letras. Para realizar un acompañamiento longitudinal del trabajo con la lectura, se discuten los datos de dos estudiantes relativos al género crónica en dos disciplinas académicas. Los resultados muestran que para las estudiantes, son herramientas de poder conocer el funcionamiento de un campo social específico, que incorpora cuestiones de género para la lectura y para la producción escrita y desarrolla la meta cognición con el objetivo de hacer uso de la literacidad crítica y utilizar, 
belong for the process of being insiders de la misma forma, las literacidades within an academic context.

dominantes en dirección de asumir Keywords: Academic literacy. Reading. una posición privilegiada en el contexto Portuguese language-discursive genre. académico.

Palabras-clave: Literacidad académica. Lectura. Lengua Portuguesa - Género discursivo.

\section{Adriana Fischer}

Instituto de Educação e Psicologia, Centro de Investigação em Educação (CIEd), Universidade do Minho - Campus de Gualtar - 4710-057 - Braga - Portugal. Telefones: +351253604249/+351253604688

E-mail: adrifischer@iep.uminho.pt

\section{Nilcéa Lemos Pelandré}

Universidade Federal de Santa Catarina

Centro de Ciências da Educação

Programa de Pós-Graduação em Educação (PPGE)

Bairro Trindade - Florianópolis, SC

CEP: 88040-900

Telefones: (48) 37219429 Fax: (48) 37218638

E-mail: nilcea@ced.ufsc.br

Recebido em: $1 / 7 / 2010$ Aprovado em: 29/10/2010 